\title{
Aortic valve implantation with the CoreValve ReValving System via left carotid artery access: First case report
}

\author{
Thomas Modine, MD, ${ }^{\mathrm{b}}$ Gilles Lemesle, MD, ${ }^{\mathrm{a}}$ Richard Azzaoui, MD, ${ }^{\mathrm{b}}$ and Arnaud Sudre, MD, ${ }^{\mathrm{a}}$ Lille, France
}

An 89-year-old man with symptomatic degenerative aortic stenosis and a history of left retropectoral pacemaker was admitted to the Hôpital Cardiologique. Dyspnea (New York Heart Association III) had altered his quality of life.

\section{CLINICAL SUMMARY}

Transthoracic echocardiography showed a $75 \mathrm{~mm} \mathrm{Hg}$ peak gradient and $0.8 \mathrm{~cm}^{2}$ surface area. Left ventricular ejection fraction was $50 \%$. Two cardiac surgeons considered the patient at high risk for conventional surgery because of his advanced age. The logistic EuroScore was $14.6 \%$. Angiography revealed severe tortuosity of the abdominal aorta and right subclavian artery. Computed tomography angiography showed type I aortic arch and calcifications of the left subclavian artery ostium. The left common carotid artery diameter was $7 \mathrm{~mm}$. Although the patient was initially considered for subclavian implantation, a heart team chose the left carotid

From the Pôle de Cardiologie, Service de Cardiologie B et Centre Hémodynamique ${ }^{\mathrm{a}}$ and Service de Chirurgie Cardio-thoracique, ${ }^{\mathrm{b}}$ Hôpital Cardiologique, Centre Hospitalier Régional et Universitaire de Lille, Lille, France.

Disclosures: None.

Received for publication Sept 20, 2009; accepted for publication March 1, 2010; available ahead of print April 12, 2010.

Address for reprints: Thomas Modine, MD, Hôpital Cardiologique, Service de Chirurgie Cardiovasculaire, Centre Hospitalier Régional et Universitaire de Lille, Bd du Pr Jules Leclercq 59037 Lille Cedex, France (E-mail: thomas.modine@chru-lille.fr).

J Thorac Cardiovasc Surg 2010;140:928-9

$0022-5223 / \$ 36.00$

Copyright (c) 2010 by The American Association for Thoracic Surgery doi:10.1016/j.jtcvs.2010.03.001 approach to implant a CoreValve Revalving System (Medtronic Inc, Minneapolis, Minn) prosthesis. At that time, a transapical approach with an Edwards-Sapien prosthesis (Edwards Lifesciences, Irvine, Calif) was not available at the Hôpital Cardiologique. A Doppler study of the carotid and vertebral arteries showed no significant disease. With the patient under local anesthesia, the left common carotid artery was surgically exposed via a 5-cm incision. Two 5-0 Prolene continuous purse sutures were made on the anterior wall of the artery to perform a transarterial implantation. On guide wire introduction, a partial noncircumferential retrograde dissection of the left carotid artery and ascending aorta was performed (Figure 1). The patient remained stable, and electrocardiography showed no modification. However, we decided to implant the prosthesis, taking into consideration the contraindication to conventional surgery. The decision had been accepted preoperatively by the staff, the patient, and the patient's family. The guide wire was retrieved and carefully placed in the true lumen. The $18 \mathrm{~F}$ sheath was inserted into the artery to proceed with the implantation. Once the balloon valvuloplasty was achieved, the aortic CoreValve Revalving System was delivered and successfully implanted. The prosthesis was well positioned with no significant residual transvalvular gradient. At that time, the aortic dissection remained (Figure 2). We considered that the dissection, which was present since the beginning of the procedure, was due to the guide wire introduction. The arterial access site was repaired surgically to exclude the dissection entry orifice. After the procedure, the patient had a transient right hemiparesis. A control cerebral computed
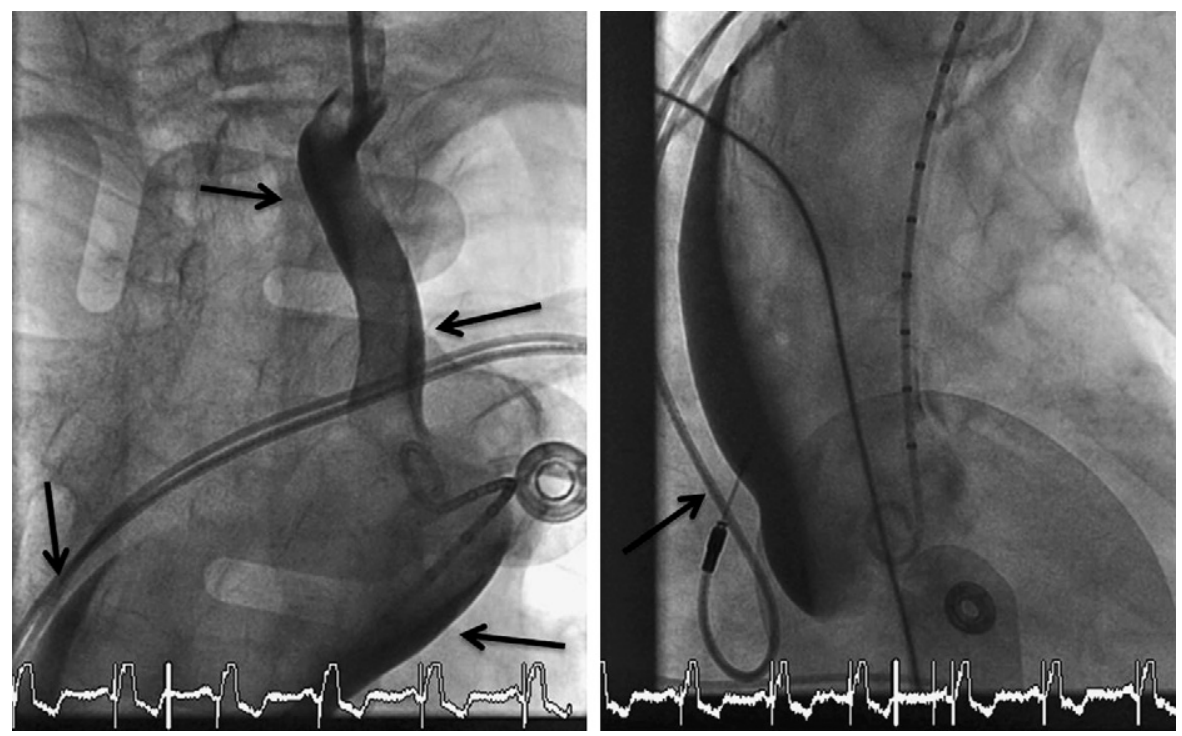

FIGURE 1. Dissection of left carotid artery and ascending aorta (arrows). 

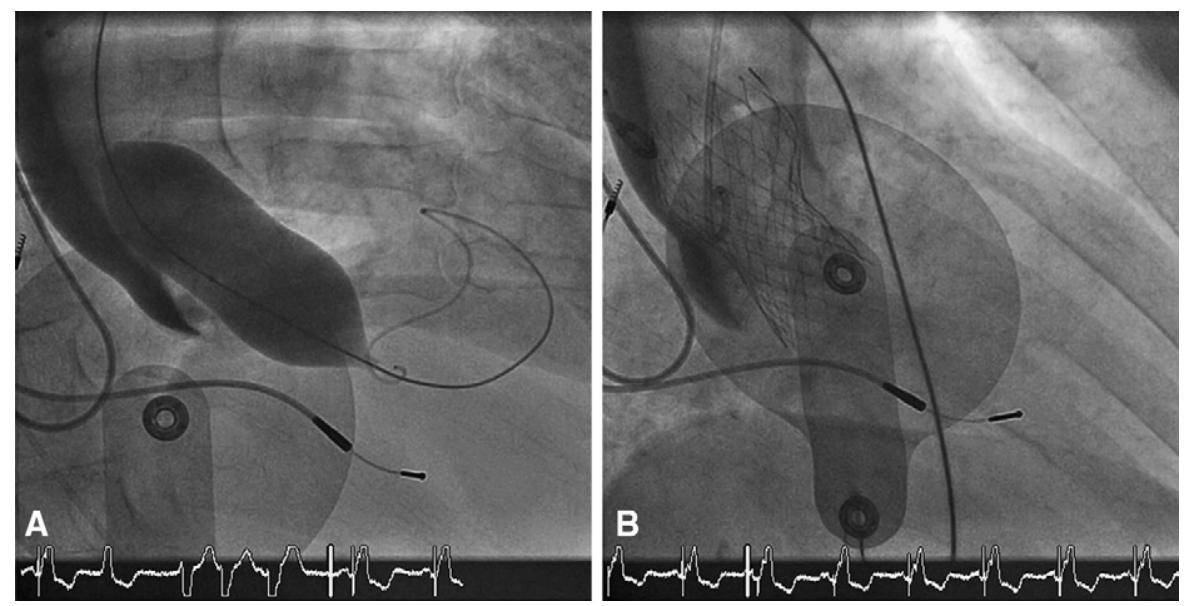

FIGURE 2. Successful balloon angioplasty (A) and implantation of the CoreValve ReValving System (B) (Medtronic Inc, Minneapolis, MN). At that time, the aortic dissection persisted.

tomography scan showed no evidence of ischemic or hemorrhagic stroke. A control angiography scan and Doppler study were also performed, which showed complete healing of the dissection. The patient's hospital stay was prolonged; however, he made a complete recovery before discharge with no neurologic symptoms. At 1 month, the patient's dyspnea had significantly improved (New York Heart Association II).

\section{DISCUSSION}

Percutaneous aortic valve implantation has become a promising option in elderly and high-risk patients. ${ }^{1-5}$ However, there are still several limitations to this technique. Indeed, both the arterial access and the ability to accurately deliver the prosthesis play a pivotal role. Tortuosity of the aorta and severe arterial disease of the iliofemoral arteries are still challenging. ${ }^{3,5}$ Subsequently, some authors have reported the feasibility of a subclavian artery or transapical approach. ${ }^{3-5}$ In the case presented, we chose the left carotid artery because of severe tortuosity of the abdominal aorta and right subclavian artery. The presence of a pacemaker may represent a high risk of infective endocarditis in a left subclavian artery approach. A right carotid artery approach also could have been considered (type I aortic arch) in the present case. At that time, the transapical approach was not available at the Hôpital Cardiologique. However, the risk of ischemic stroke is a major pitfall of this approach. Therefore, a complete evaluation of the cerebral arteries and circle of Willis is required. Computed tomography angiography and Doppler study of both the carotid and vertebral arteries were performed before the procedure to ensure that the vessel was of adequate size to fit the sheath and that there was no significant atherosclerotic disease in the access and other cerebral arteries. The presence of significant stenosis in the cerebral arteries should be a contraindication for this approach because of the high risk of ischemic stroke. The aortic CoreValve Revalving System was successfully implanted, and the left carotid artery approach provided good implantation stability and ease of delivery. We believe this approach is more comfortable for patients under general anesthesia. Neurologic monitoring (transcranial Doppler, electroencephalography) may be an interesting tool in these patients.

\section{CONCLUSIONS}

We report the first case of an aortic CoreValve Revalving System implantation via left carotid artery access. Because of the potential associated morbidity, this approach may be considered, as a last resort, after careful cerebral arterial evaluation, when other access routes are unavailable to treat patients who are eligible for percutaneous aortic valve implantation.

\section{References}

1. Cribier A, Eltchaninoff H, Bash A, Borenstein N, Tron C, Bauer F, et al. Percutaneous transcatheter implantation of an aortic valve prosthesis for calcific aortic stenosis: first human case description. Circulation. 2002;106:3006-8.

2. Grube E, Schuler G, Buellesfeld L, Gerckens U, Linke A, Wenaweser P, et al. Percutaneous aortic valve replacement for severe aortic stenosis in high-risk patients using the second- and current third-generation self-expanding CoreValve prosthesis: device success and 30-day clinical outcome. J Am Coll Cardiol. 2007;50: 69-76

3. Zierer A, Wimmer-Greinecker G, Martens S, Moritz A, Doss M. The transapical approach for aortic valve implantation. J Thorac Cardiovasc Surg. 2008;136: 948-53.

4. Piazza N, Grube E, Gerckens U, den Heijer P, Linke A, Luha O, et al. Procedural and 30-day outcomes following transcatheter aortic valve implantation using the third generation (18 Fr) CoreValve revalving system: results from the multicentre, expanded evaluation registry 1-year following CE mark approval. EuroIntervention. 2008;4:242-9.

5. Asgar AW, Mullen MJ, Delahunty N, Davies SW, Dalby M, Petrou M, et al. Transcatheter aortic valve intervention through the axillary artery for the treatment of severe aortic stenosis. J Thorac Cardiovasc Surg. 2009;137:773-5. 